\title{
As agências reguladoras em resposta à crise da COVID-19
}

\author{
Sérgio Guerra 1 \\ Natasha Schmitt Caccia Salinas 1 \\ Lucas Thevenard Gomes 1
}

1 Fundação Getulio Vargas / Escola de Direito do Rio de Janeiro, Rio de Janeiro / RJ - Brasil

\begin{abstract}
Este artigo tem por objetivo analisar as respostas das agências reguladoras federais para o enfrentamento da crise de saúde pública gerada pelo novo coronavírus. Parte-se do entendimento de que a avaliação empírica dos padrões de resposta evidenciados pelas agências durante a crise da COVID-19 cumpre um papel importante no aprimoramento da função pública. Em primeiro lugar, porque oferece subsídios para que a própria atividade regulatória se adapte de forma mais célere às necessidades do atual momento de crise. Em segundo, porque o contexto excepcional gerado pela pandemia coloca em evidência alguns traços essenciais da atividade regulatória: suas condições de exercício e funcionalidades, suas limitações e potencialidades e, sobretudo, sua importância para a minimização de danos em cenários marcados por instabilidade estrutural. Os dados utilizados no presente estudo foram extraídos do Diário Oficial da União (DOU) e dos sítios eletrônicos das 11 agências reguladoras federais. Para a presente análise, foram selecionadas apenas as medidas com efetivo impacto regulatório sobre o setor regulado. Identificamos uma significativa heterogeneidade no volume de respostas das agências, em parte relacionada a diferenças setoriais, mas sobretudo decorrente de assimetrias na capacidade institucional desses órgãos. Identificamos também uma heterogeneidade no conteúdo das respostas das agências a problemas regulatórios semelhantes, evidenciando falhas de coordenação regulatória que precisam ser urgentemente solucionadas.
\end{abstract}

Palavras-chave: COVID-19; agências reguladoras; medidas regulatórias emergenciais; capacidade institucional; coordenação regulatória.

\section{Las agencias reguladoras en respuesta a la crisis de la COVID-19}

El objetivo de este artículo es analizar las respuestas de las agencias reguladoras federales para enfrentar la crisis de salud pública creada por el nuevo coronavirus. Entendemos que la evaluación empírica de los protocolos de respuesta llevados a cabo por las agencias durante la crisis de la COVID-19 cumple un papel importante para perfeccionar la función pública. En primer lugar, porque colabora a que la propia actividad regulatoria se adapte de forma más rápida a las necesidades del momento actual de crisis. En segundo lugar, porque el contexto excepcional producido por la pandemia pone en evidencia algunos rasgos esenciales de la actividad regulatoria: sus condiciones de ejercicio y operaciones, sus limitaciones y potencialidades y, sobre todo, su importancia para la minimización de daños en momentos de inestabilidad estructural. Los datos utilizados en el presente estudio provienen del Diário Oficial da União (DOU), así como de los sitios web de las once agencias reguladoras federales. Hemos seleccionado para este análisis solamente las medidas de impacto regulatorio efectivo sobre el sector regulado. Identificamos una heterogeneidad significativa en el volumen de respuestas de las agencias, que se relaciona, en parte, con diferencias sectoriales, pero sobre todo resultante de asimetrías en la capacidad institucional de esos órganos. Identificamos también una heterogeneidad de contenido en las respuestas de las agencias ante algunos problemas regulatorios semejantes, lo que demuestra deficiencias en la coordinación regulatoria que deben solucionarse urgentemente.

Palabras clave: COVID-19; agencias reguladoras; medidas regulatorias de emergencia; capacidad institucional; coordinación regulatoria. 


\section{Regulatory agencies in response to the COVID-19 crisis}

This article aims to examine the responses of federal regulatory agencies to the public health crisis - the COVID-19 pandemic. We adhere to the understanding that an empirical evaluation of the patterns of response manifested by the agencies during the pandemic plays an important role in the improvement of public function. First, because it aids the task of adapting regulatory activities more quickly to the needs of the current situation. Secondly, because the context of exceptionality created by the pandemic highlights essential features of the regulatory activity in itself: its conditions of execution and functionalities, limitations and potentialities, and, most of all, its importance for minimizing losses in scenarios of structural instability. The data used in this study was gathered from the Official Gazette Diário Oficial da União (DOU) and the websites of the eleven regulatory federal agencies. In our analysis, we only selected measures with an impact on the regulated sector. We found significant heterogeneity in the number of agency responses, partly related to sectorial differences, but mostly arising from asymmetries of institutional capability among these bodies. We also found heterogeneity of content in the responses given by agencies to similar regulatory problems, which suggests the existence of failures in regulatory coordination in urgent need of a solution.

Keywords: COVID-19; regulatory agencies; emergency regulations; institutional capacity; regulatory coordination.

\section{INTRODUÇÃO}

Com o agravamento da crise da COVID-19, as agências reguladoras passaram a atender a um alto volume de demandas da sociedade, dos agentes econômicos regulados e dos demais órgãos e entidades do próprio governo federal.

Antes da pandemia, as agências reguladoras vinham adotando medidas para se ajustar aos novos comandos impostos pelo Legislativo e pelo Executivo a fim de orientar seus processos decisórios (Salinas \& Brelaz, 2020). Do primeiro surgiram, por exemplo, exigências para a realização de consultas públicas e análise de impacto regulatório nos processos normativos das agências (Lei no 13.848, 2019). Já o segundo buscou imprimir um ritmo às ações regulatórias das agências ao lhes exigir prazos para conceder e rever atos de liberação econômica (Lei no 13.874, 2019). Esse mesmo poder adotou medidas que afetaram diretamente a agenda regulatória das agências, como quando determinou que elas revisassem todo o estoque regulatório, revogando normas obsoletas e/ou excessivamente custosas aos agentes regulados (Decreto $\mathrm{n}^{\circ} 10.139,2019$ ).

Além de ter de atender a essas novas pautas, as agências reguladoras continuaram a exercer suas funções regulatórias típicas, como editar normas, fiscalizar ações dos regulados, impor sanções e resolver conflitos (Marques, 2003). Com o quadro de calamidade pública decorrente do novo coronavírus, entretanto, muitas dessas atividades típicas de regulação tiveram de ser suspensas para que as agências pudessem exercer aquelas que se impuseram no novo cenário de riscos e incertezas.

As agências que regulam os setores de saúde e vigilância sanitária, diretamente atingidas pela pandemia, foram instadas a oferecer soluções para a prevenção e o tratamento da doença. Agências que regulam serviços públicos como os de transporte, telecomunicações, fornecimento de energia e distribuição de gás, por exemplo, se viram demandadas a adotar medidas para garantir que tais serviços não sejam descontinuados a despeito da queda de demanda, espontânea ou provocada por decisões administrativas. Essas agências também devem atuar para evitar ou desfazer o eventual desequilíbrio das relações entre agentes econômicos regulados e usuários. A queda de demanda ou a inadimplência dos usuários compromete diretamente a liquidez das concessionárias, de modo 
que medidas regulatórias devem ser adotadas para garantir a continuidade dos serviços e preservar direitos e obrigações de ambas as partes.

Diante desse quadro, no lugar de ações regulatórias planejadas (Coglianese \& Walters, 2016), surgem medidas emergenciais; no lugar de processos regulatórios racionais (Baldwin, Cave, \& Lodge, 2012) e participativos (Kerwin \& Furlong, 2018), surgem decisões incrementais. Exigências processuais de agentes regulados são suspensas, extintas ou prorrogadas, para que as agências possam concentrar seus esforços em ações de combate à pandemia. Do mesmo modo, obrigações contratuais dos regulados são revistas, a fim de que novos acordos e termos de compromisso sejam celebrados no seu lugar.

Neste artigo, pretendem-se analisar as respostas das agências reguladoras federais ao enfrentamento da crise de saúde pública gerada pelo novo coronavírus. O presente estudo parte do entendimento de que a avaliação empírica dos padrões de resposta oferecidos pelas agências durante a crise cumpre um papel importante no aprimoramento da função pública. Em primeiro lugar, porque oferece subsídios para que a própria atividade regulatória se adapte de forma mais célere às necessidades do atual momento de crise. Em segundo, porque o contexto excepcional gerado pela pandemia coloca em evidência alguns traços essenciais da atividade regulatória: suas condições de exercício e funcionalidades, suas limitações e potencialidades e, sobretudo, sua importância para a minimização de danos em cenários marcados por instabilidade estrutural.

Com esses objetivos em vista, este artigo busca, inicialmente, mensurar as respostas oferecidas pelas agências. Em seguida, analisa-se o conteúdo das medidas adotadas por todas as agências reguladoras federais em decorrência da pandemia do novo coronavírus. Na sequência, serão feitas considerações preliminares sobre os limites e as possibilidades das ações desenvolvidas pelas agências no combate à crise da COVID-19.

\section{MEDINDO AS RESPOSTAS REGULATÓRIAS}

Com o objetivo de avaliar o comportamento das agências reguladoras diante da crise, construímos um banco de dados sobre as medidas adotadas por elas em resposta à epidemia do novo coronavírus. Os dados foram coletados dos sítios eletrônicos das agências e das publicações do Diário Oficial da União (DOU). Para a contagem das medidas adotadas pelas agências, foram considerados atos normativos e decisões administrativas - notas técnicas, despachos, decisões, ofícios - com efetivo impacto regulatório sobre o setor regulado. Foram excluídas da presente análise, portanto, medidas de mera gestão de pessoal ou cujos efeitos fossem predominantemente internos às agências normas disciplinando regras de teletrabalho, reuniões por videoconferência, entre outras. Assim, as mensurações a seguir buscam evidenciar o grau de responsividade das agências reguladoras à crise.

Nos 4 primeiros meses de combate à pandemia, foram identificadas 307 medidas adotadas pelas agências reguladoras. ${ }^{1}$ Os Gráficos 1 e 2 mostram a evolução histórica dessas medidas ao longo do tempo. Os dados revelam que as respostas das agências se tornaram expressivas no mês de março, notadamente a partir da semana iniciada no dia 16. Além de ter havido uma forte concentração de medidas nos meses de março e abril, os critérios regulatórios estão também majoritariamente reunidos em algumas agências.

${ }^{1}$ A data de corte da presente análise é o dia 30 de junho de 2020. 


\section{GRÁFICO 1 MEDIDAS DE COMBATE À COVID-19}

\section{Evolução mensal}



Fonte: Elaborado pelos autores.

GRÁFICO 2 MEDIDAS DE COMBATE À COVID-19 POR AGÊNCIA

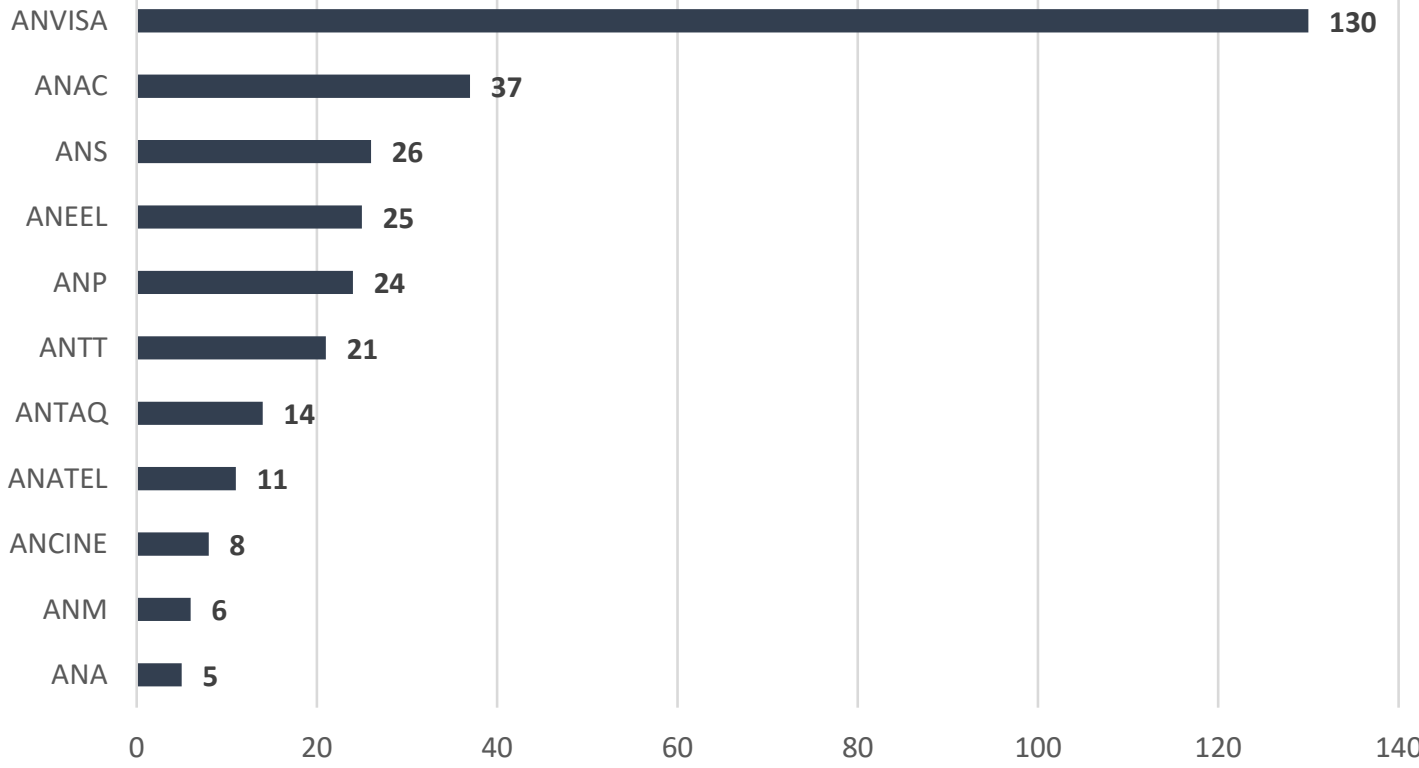

Fonte: Elaborado pelos autores. 
Chama a atenção o fato de que praticamente todas as agências reguladoras ofereceram algum tipo de resposta à crise gerada pela pandemia. Como não foram selecionadas normas que tratassem exclusivamente de temas internos às agências, como teletrabalho ou gestão de servidores, os dados mostram que a crise impactou diretamente os setores regulados.

A Agência Nacional de Vigilância Sanitária (ANVISA) se destaca como o órgão com o maior número de medidas que tratam do coronavírus, como era esperado em razão dos temas sob sua competência. Como será discutido na terceira parte, o surto de coronavírus evidenciou que a Anvisa tem oferecido respostas céleres no contexto da crise. Além disso, suas ações têm sido essenciais para orientar decisões de diversas instituições do governo federal, incluindo outras agências reguladoras. O Gráfico 3 mostra como o número total de referências ao coronavírus no DOU evoluiu ao longo das semanas.

\section{GRÁFICO 3 ATOS NO DOU COM MENÇÃO À COVID-19 OU CORONAVÍRUS}

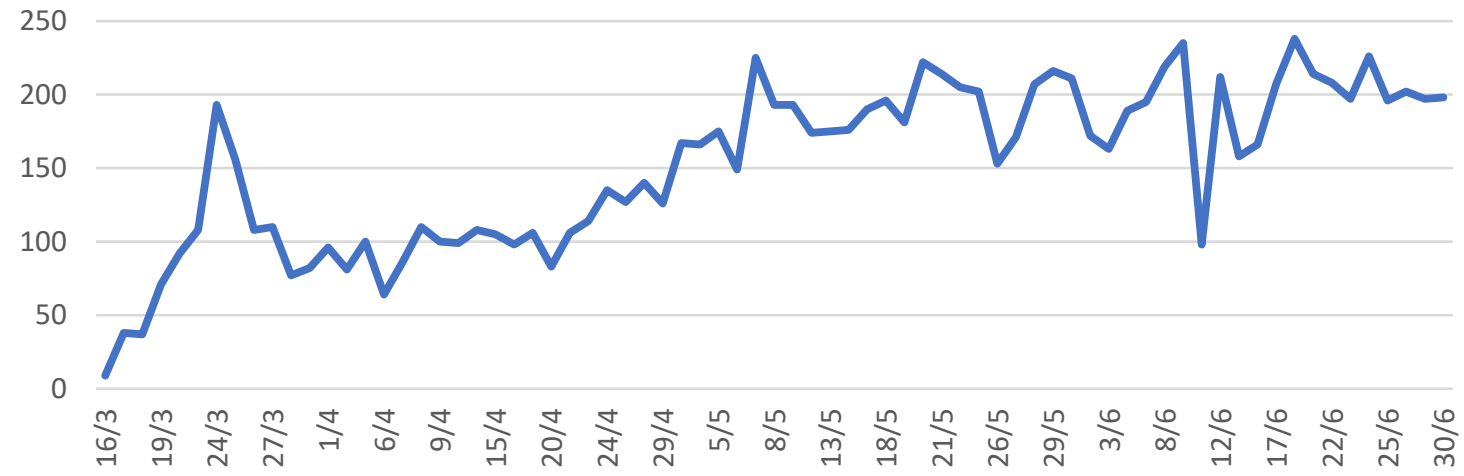

\section{—COVID ou Coronavírus}

Fonte: Elaborado pelos autores.

Buscando medir a atenção que as autoridades regulatórias têm atribuído ao tema, realizou-se também um levantamento do número de chamadas, na página de notícias do site das agências, que tenha tratado diretamente do coronavírus desde a semana do dia 9 de março. ${ }^{2} \mathrm{O}$ resultado revela maior destaque ao tema pelas Agência Nacional de Saúde Suplementar (ANS), Agência Nacional de Aviação Civil (ANAC) e ANVISA. As 3 primeiras são também as agências que adotaram, até o presente momento, o maior número de medidas no combate à COVID-19.

${ }^{2}$ Apenas notícias que tratassem expressamente da pandemia, mencionando a doença no corpo do texto, foram levadas em consideração. 
RAP | As agências reguladoras em resposta à crise da COVID-19

\section{GRÁFICO 4 NOTÍCIAS SOBRE COVID-19 NOS SITES DAS AGÊNCIAS}

— Menção à COVID-19 — Outros


Fonte: Elaborado pelos autores. 
$\mathrm{Na}$ seção seguinte, analisa-se o conteúdo propriamente dito das medidas adotadas pelas agências reguladoras federais em decorrência da pandemia do novo coronavírus.

\section{AS RESPOSTAS DAS AGÊNCIAS À COVID-19}

Analisando o conjunto de respostas das agências reguladoras, identificam-se, inicialmente, ações de flexibilização ou de suspensão de certas funções exercidas por esses órgãos. Em seguida, verificam-se medidas de enfrentamento direto à pandemia, como intervenções para prevenção do contágio e o tratamento da doença. Por fim, identifica-se um conjunto de operações visando garantir a continuidade dos serviços e das atividades econômicas regulados, a despeito da crise econômica provocada pela pandemia. Quanto a esse tema, podemos identificar que tais ações se subdividem em 3 finalidades principais: flexibilizar requisitos técnicos e operacionais que regem atividades econômicas e serviços públicos, dar suporte financeiro aos agentes regulados e proteger os interesses de usuários ou consumidores de serviços e atividades.

A seguir, apresentamos as medidas de combate à COVID-19 com base nesses eixos principais de ação das agências. O conteúdo de cada ação foi analisado para determinar que categorias estavam envolvidas em cada deliberação. Essa classificação não seguiu fronteiras rígidas e estanques - em diversos casos, por exemplo, uma mesma medida foi classificada como mais um tipo de ação, já que, de fato, aquela medida apresentava mecanismos que atendiam a mais de um dos objetivos acima elencados. ${ }^{3}$

\subsection{Flexibilização das Funções das Agências}

A primeira classificação identificada neste trabalho diz respeito às ações de flexibilização das funções das agências. ${ }^{4} \mathrm{O}$ Gráfico 5 apresenta a quantidade de ações desse tipo por agência.

\section{GRÁFICO 5 FLEXIBILIZAÇÃO DAS FUNÇÕES DAS AGÊNCIAS}



Fonte: Elaborado pelos autores.

\footnotetext{
${ }^{3}$ A soma das tabelas abaixo produzirá um volume total de itens superior ao número total de medidas apresentados nos gráficos anteriores. Trata-se de uma consequência lógica da adoção de critérios de classificação não excludentes.

${ }^{4}$ Neste trabalho, excluímos da amostra as medidas de mera gestão interna, como regras de teletrabalho. Assim, quando nos referimos a medidas de flexibilização das funções das agências, estamos tratando de ações que geram impactos diretos sobre os agentes regulados, como é o caso de medidas que suspendem prazos ou dispensam a entrega de documentos, entre outras.
} 
Um número considerável de medidas adotadas pelas agências não trata diretamente do enfrentamento da pandemia. Em diversos casos, o coronavírus é apresentado como pano de fundo para a adoção de medidas que respondem aos efeitos indiretos da crise, ou seja, às restrições geradas para o exercício das atividades regulatórias das próprias agências, ocasionando suspensões de prazos processuais, relaxamento de obrigações para os regulados, suspensão de vistorias e fiscalizações etc.

As agências têm deixado de exercer parte de suas funções regulatórias típicas para gerir os impactos da pandemia. Essas autarquias têm flexibilizado ou mesmo suspendido parte de suas atribuições, seja para atender a recomendações ou determinações de isolamento social, seja para concentrar seus esforços na minimização dos efeitos da pandemia sobre a prestação dos serviços regulados.

Para tanto, as agências têm prorrogado prazos para concluir atos de liberação econômica não relacionados à pandemia, como a concessão de habilitações, certificados, autorizações, licenças, entre outros.

A Agência Nacional de Petróleo, Gás Natural e Biocombustíveis (ANP) adiou eventos, consultas e audiências públicas; suspendeu vistorias (Resolução $n^{\circ}$ 812, 2020), auditorias e leilões; postergou prazos para a emissão de certificados e a celebração de atos contratuais. Já a Agência Nacional de Transportes Terrestres (ANTT) prorrogou fiscalizações (Portaria no 102, 2020; Portaria $n^{\circ} 117,2020$ ), flexibilizou prazos contratuais (Resolução $\mathrm{n}^{\circ} 5.979,2020$ ), suspendeu processos administrativos sancionadores (Resolução n 5.878, 2020) e substituiu reuniões e audiências públicas presenciais por virtuais (Resolução no 5.891, 2020).

A Agência Nacional de Aviação Civil (ANAC) prorrogou a vigência de habilitações, certificados, autorizações, averbações, credenciamentos, treinamentos e exames exigidos na aviação civil. Do mesmo modo, suspendeu por tempo indeterminado exames teóricos para licenças e habilitações de aeronautas, mecânicos de manutenção aeronáutica, comissários e despachantes operacionais de voo, além de ter autorizado Centros de Instrução da Aviação Civil a ministrar aulas teóricas a distância. A Agência Nacional de Transportes Aquaviários (ANTAQ) também cancelou um leilão e suspendeu ou prorrogou prazos processuais (Portaria no 109, 2020; Resolução no 7.784, 2020).

A ANVISA, por sua vez, suspendeu prazos referentes a atos de liberação econômica não relacionados à pandemia (Resolução no 355, 2020), assim como a Agência Nacional de Energia Elétrica (ANEEL) adiou a tramitação de processos (Portaria no 6.310, 2020) e postergou diversos leilões (Portaria no 134, 2020). A Agência Nacional de Mineração (ANM) prorrogou prazos processuais diversos e a Agência Nacional de Telecomunicações (ANATEL) simplificou processos de certificação. A Agência Nacional do Cinema (ANCINE) suspendeu temporariamente prazos para a prestação de contas de projetos audiovisuais (Portaria no 151-E, 2020), ao passo que a Agência Nacional de Águas (ANA) prorrogou os prazos para outorgas de direito de uso de recursos hídricos (Resolução $\mathrm{n}^{\circ}$ 21, 2020).

A flexibilização das funções ordinariamente exercidas pelas agências tem, por outro lado, proporcionado ganhos de eficiência a certos órgãos reguladores. A ANVISA (2020), ao simplificar processos para autorização de importação, produção e distribuição de produtos relacionados ao enfrentamento da pandemia, reduziu significativamente seu tempo de resposta. A ANA (2020) diminuiu seu passivo de pedidos de regularização de usos de água da União, possibilitado pela diminuição da entrada de novos pedidos durante a pandemia. Já a ANEEL (2020) afirmou ter economizado recursos durante a pandemia e obtido ganhos de produtividade com a introdução do teletrabalho de sua equipe. 


\subsection{Enfrentamento Direto da Pandemia}

A segunda classificação identificada neste trabalho trata das ações de enfrentamento direto da pandemia, representadas no Gráfico 6.

\section{GRÁFICO 6 ENFRENTAMENTO DIRETO DA PANDEMIA}



Fonte: Elaborado pelos autores.

A ANVISA é, massivamente, a agência mais ativa no combate à pandemia do novo coronavírus. Das 149 medidas levantadas, 116 (77,8\% do total) foram adotadas por essa agência reguladora.

Em termos de escopo do objeto, as medidas da ANVISA alcançaram um amplo conjunto de assuntos. Podem-se citar como exemplos: padrões para produção e distribuição de medicamentos para o combate ao coronavírus; controle da fabricação, da importação e da comercialização de equipamentos e dispositivos médicos necessários ao tratamento de pacientes com a doença; controle sanitário em portos, aeroportos e fronteiras; fabricação e distribuição de saneantes (como álcool em gel); critérios técnicos para exames e triagem do coronavírus utilizando sangue, células, tecidos e órgãos; orientações sobre ensaios clínicos e o uso experimental de opções para o enfrentamento da doença; ${ }^{5}$ medidas relativas à continuidade dos serviços de vacinação durante a pandemia; ações para a prevenção de contaminação de idosos em instituições de longa permanência (asilos); medidas de impacto geral, procedimentais, entre outras.

Um fator relevante para o peso predominante da ANVISA no combate à COVID-19 é, evidentemente, a pertinência temática, tendo em vista que questões sanitárias cumprem um papel central no combate e na contenção do novo coronavírus. A ênfase atual na prevenção do contágio faz do coronavírus uma questão essencialmente de vigilância sanitária.

\footnotetext{
${ }^{5}$ A exemplo da autorização do uso experimental de sulfato de hidroxicloroquina/azitromicina di-hidratada (Resolução Especial no 922 , 2020).
} 
Mais relevante para o atual cenário de crise, contudo, é a habilidade que cada órgão público tem de antecipar choques e oferecer respostas céleres (Matthews, 2012). Nesse quesito, a Anvisa também se revelou uma agência com alto grau de responsividade, pois criou, em janeiro, por meio da Portaria no 74 (2020), um grupo de emergência em saúde pública destinado a monitorar e conduzir ações referentes ao novo coronavírus. A atuação da instituição no combate à COVID-19 começou, portanto, muito antes do tema passar a ser tratado pela mídia e pela população como uma ameaça concreta e iminente à saúde pública brasileira; antes até da questão começar a se impor sistematicamente aos demais órgãos do governo federal (Croda \& Garcia, 2020). Assim, quando os efeitos da crise se tornaram mais perceptíveis, a agência já havia desenvolvido uma "massa crítica" de processos e conhecimentos para responder à crise.

A esse respeito, é relevante destacar que a Anvisa está atenta ao cenário regulatório internacional, fazendo frequente uso de textos e estudos produzidos por entidades de pesquisa estrangeiras (Pereira, 2014). Assim, já vinha acompanhando os acontecimentos internacionais acerca do coronavírus e buscando informações junto a outros países antes dos atos da presidência da República e do serviço exterior brasileiro que requisitaram formalmente o auxílio técnico da China e de outros países.

Além da ANVISA, a ANS também adotou medidas de enfrentamento direto à pandemia. Uma importante medida foi a edição da Resolução Normativa no 453 (2020) e da Resolução Normativa $n^{\circ} 458$ (2020), que obrigaram os planos de saúde a garantir a cobertura de testes diagnósticos para detecção do coronavírus e do tratamento da doença.

A ANS, de igual modo, adotou medidas para facilitar os serviços de telessaúde na rede suplementar. O serviço de telemedicina já era regulamentado pelo Conselho Federal de Medicina (CFM) desde 2002 (Resolução no 1.643, 2002). Em ofício do CFM ao Ministério da Saúde, datado de 19 de março de 2020, esse órgão reconheceu a possibilidade e a eticidade da telemedicina para os serviços de teleorientação, telemonitoramento e teleconsulta. Em seguida, a presidência da República editou a Portaria no 467 (2020), dispondo sobre as ações de telemedicina, e o Congresso Nacional aprovou a Lei no 13.989 (2020), autorizando o uso de telemedicina enquanto perdurar a crise.

Simultaneamente, os Conselhos Federal de Psicologia, Fonoaudiologia, de Nutricionistas e de Fisioterapia e Terapia Ocupacional editaram regras próprias para os serviços de telessaúde. É nesse contexto que a ANS adotou medidas para agilizar os serviços de telessaúde na rede suplementar. Uma ação importante foi a decisão de dispensar operadoras e prestadores de alteração dos contratos vigentes para incluir serviços de telessaúde, sendo suficiente a mera comunicação entre as partes.

As agências reguladoras de transporte, em especial a ANAC e a ANTT, flexibilizaram regras de logística para auxiliar o transporte não só de passageiros contaminados, mas também de insumos, materiais, remédios e equipamentos de saúde.

Destacam-se, assim, as iniciativas da ANAC para flexibilizar as regras de autorização de operação de táxis aéreos (Portaria no 880, 2020), aeronaves adaptadas com dispositivos de isolamento de pacientes (Decisão no 83, 2020) e helicópteros (Resolução no 559, 2020).

Já a ANTT flexibilizou, por meio da Resolução no 5.875 (2020), as exigências para o transporte fracionado de etanol ou solução de etanol com concentrações iguais ou superiores a 70\%. Esse produto, essencial para a prevenção da contaminação pela COVID-19, por ser considerado perigoso, estaria sujeito a normas regulatórias mais restritas em circunstâncias não emergenciais.

Percebe-se aqui uma atuação coordenada entre agências de transporte e a ANVISA. Por um lado, as medidas de vigilância sanitária determinadas pela ANVISA são amplamente aceitas pela 
ANAC, pela ANTT e pela ANTAQ como essenciais para garantir a segurança de passageiros em portos, aeroportos e rodovias. Por outro, a ANVISA tem se beneficiado da flexibilização de regras, sobretudo editadas pela ANAC e pela ANTT, para o transporte de insumos e materiais de prevenção e tratamento da doença.

Foram também identificadas iniciativas pontuais adotadas pela ANATEL, pela ANA e pela ANEEL para o enfrentamento direto da pandemia. A primeira autorizou a criação do código telefônico 1960 para atendimento de pacientes que necessitam de tratamento emergencial contra a COVID-19. Além disso, participou da Rede Conectada MCTIC, uma iniciativa do Ministério de Ciência e Tecnologia para a contratação de serviços de internet para todas as unidades de saúde (Portaria n ${ }^{\circ} 1.153,2020$ ). A ANA, por sua vez, criou, por meio da Portaria no 165 (2020), o comitê gestor do projeto-piloto Monitoramento Covid Esgotos, composto pela agência, pelo Instituto Mineiro de Gestão de Águas (Igam) e pelo Instituto Nacional de Ciência e Tecnologia/Estações de Tratamento Sustentáveis (INCT/ ETEs Sustentáveis), sediado e coordenado pela Universidade Federal de Minas Gerais (UFMG). O projeto tem por objetivo monitorar a presença do vírus nos efluentes de Belo Horizonte e Contagem, indicando áreas de maior incidência de transmissão. Já a ANEEL aprovou projetos de eficiência energética em hospitais da Bahia e de Pernambuco.

Para enfrentamento da pandemia, as agências reguladoras se viram obrigadas a executar ações de prevenção da doença determinadas por outros órgãos da administração pública. $O$ fechamento de portos, aeroportos e fronteiras terrestres, por exemplo, foi determinado por portarias diversas de órgãos da presidência da República. ${ }^{6}$ Sobre essas decisões, a ANVISA exerceu um papel consultivo essencial.

\subsection{Garantia da Continuidade de Serviços Públicos e de Atividades Essenciais}

Uma das atribuições essenciais das agências reguladoras é garantir que serviços públicos e atividades econômicas por elas regulados sejam prestados de forma satisfatória. Leis e regulamentos definem as caraterísticas essenciais de um serviço adequado. A lei que rege as concessões de serviços públicos estabelece, por exemplo, que serviço adequado é aquele que satisfaz às "condições de regularidade, continuidade, eficiência, segurança, atualidade, generalidade, cortesia na sua prestação e modicidade das tarifas" (Lei no 8.987, 1995). Competem às agências reguladoras definir, por meio de normativos diversos, a forma como os serviços devem ser prestados para atender a esses parâmetros legais.

Em circunstâncias normais, todas essas condições para a prestação de um serviço adequado devem coexistir de forma harmoniosa. Não basta, por exemplo, que um serviço não seja interrompido. Ele deve ser prestado de forma regular, a um preço razoável, com a melhor tecnologia disponível etc.

No contexto de pandemia, no entanto, as agências reguladoras se viram obrigadas a flexibilizar as condições de prestação dos serviços para impedir sua interrupção. Diante de circunstâncias tão adversas, tornou-se mais importante garantir a continuidade do serviço do que sua qualidade e regularidade tal como exigidas em contextos de normalidade.

\footnotetext{
${ }^{6}$ Por exemplo, a Portaria conjunta no 152 (2020), dos ministros de Estado Chefe da Casa Civil da presidência da República, de Justiça e Segurança Pública, da Infraestrutura e da Saúde proibiu temporariamente a entrada por via aérea no país de estrangeiros de todas as nacionalidades. A Portaria $\mathrm{n}^{\circ} 47$ (2020) restringiu de forma temporária o embarque e o desembarque, em portos brasileiros, de todos os estrangeiros, independentemente da nacionalidade.
} 
Para garantir a continuidade dos serviços públicos, as agências foram forçadas, primeiramente, a flexibilizar as regras de prestação exigidas dos regulados. Quase todas as agências reguladoras de serviços públicos e atividades econômicas, cada qual a seu modo, flexibilizaram as condições de prestação visando preservar sua continuidade.

Observam-se, além disso, dois outros tipos de ações adotadas pelas agências para garantir a continuidade dos serviços regulados. Para aqueles em que houve abrupta queda de demanda, algumas agências adotaram medidas paliativas para mitigar os efeitos econômicos da pandemia sobre as empresas prestadoras. Além disso, ainda que de forma menos recorrente, observamos também medidas adotadas para garantir a continuidade da prestação de serviços públicos aos usuários mais afetados economicamente pela pandemia.

\subsubsection{Flexibilização das condições de prestação de serviços e exercício da atividade econômica regulada}

Os impactos da pandemia tornaram inevitáveis a flexibilização das condições de prestação dos serviços determinados pelas agências reguladoras. O Gráfico 7 apresenta a quantidade de ações desse tipo por agência.

\section{GRÁFICO 7 FLEXIBILIZAÇÃO DE SERVIÇOS E ATIVIDADES}



Fonte: Elaborado pelos autores.

Visando enfrentar de forma célere a pandemia, a ANVISA flexibilizou diversos atos de liberação econômica para produção, importação, venda e distribuição de insumos farmacêuticos, medicamentos e produtos hospitalares. Assim, dispensou de autorização prévia a produção e a venda de álcool em gel por empresas e instituições diversas (Resolução de Diretoria Colegiada n 347, 2020, e Resolução de Diretoria Colegiada no 350, 2020), eximiu de registro a produção de equipamentos médicos prioritários no combate à COVID-19 (Resolução de Diretoria Colegiada no 356, 2020), autorizou 
laboratórios federais de defesa agropecuária a realizar análises para diagnóstico da COVID-19 (Resolução de Diretoria Colegiada no 364, 2002), permitiu a importação de equipamentos usados para UTI, entre outros.

No setor de transportes, alguns serviços foram efetivamente suspensos, como o transporte rodoviário internacional de passageiros (Resolução ANTT n 5.875, 2020) e de embarcações com objetivos recreativos (Resolução ANTAQ no 7.653, 2020). O transporte rodoviário interestadual, por sua vez, foi suspenso por alguns estados e municípios, contrariando posição da ANTT por manter a continuidade do serviço. ${ }^{7}$

A maioria dos serviços, no entanto, foi mantida, ainda que sob condições de prestação diversas. O número de voos nacionais foi reduzido em mais de $90 \% .{ }^{8}$ Coube à ANAC, portanto, negociar com as companhias aéreas a manutenção de uma malha aérea mínima que garantisse a ligação entre todos os estados. A ANAC também flexibilizou regras para as companhias aéreas alterarem horários e itinerários de viagem, bem como as desobrigou de oferecer assistência material quando não forem responsáveis pelo cancelamento dos voos (Resolução n 556, 2020). A ANTT, por meio da Resolução $\mathrm{n}^{\circ} 5.875$ (2020), autorizou as concessionárias de transporte rodoviário a suprimir certas viagens e interromper serviços por impraticabilidade temporária de itinerário. A ANTAQ manteve a navegação em território nacional, exigindo, no entanto, a limitação da ocupação de passageiros em $50 \%$ da capacidade da embarcação.

A ANS, por sua vez, decidiu prorrogar os prazos máximos, definidos pela Resolução nº 259 (2011), para a realização de consultas, exames, terapias e cirurgias não urgentes. Também foram suspensos os atendimentos em regime de hospital-dia ${ }^{9}$ e de internação eletiva. Como visto, a agência autorizou a cobertura de serviços remotos e de telessaúde ao setor suplementar.

Do mesmo modo, a ANEEL dispensou as distribuidoras de energia de certos serviços como atendimento presencial ao público, envio de faturas mensais impressas, disponibilização da estrutura de arrecadação para o pagamento de faturas, observância de prazos para devolução de valores indevidamente recebidos, realização de vistorias em unidades consumidoras, entre outros (Resolução $\left.\mathrm{n}^{\circ} 878,2020\right)$.

Já a ANP dispensou os distribuidores de combustíveis líquidos e os de combustíveis de aviação da manutenção de estoques mínimos (Resolução ${ }^{\circ} 812,2020$ ), bem como liberou a queima extraordinária de gás natural em campos de pequena produção.

\subsubsection{Suporte financeiro aos agentes regulados}

Para garantir que serviços públicos e atividades econômicas essenciais não fossem interrompidos durante a crise, as agências adotaram medidas de suporte econômico e financeiro aos agentes regulados. O Gráfico 8 apresenta a quantidade de ações desse tipo por agência.

\footnotetext{
${ }^{7}$ A Confederação Nacional do Transporte (CNT) ajuizou, no Supremo Tribunal Federal (STF), a Arguição de Descumprimento de Preceito Fundamental (ADPF) $n^{\circ} 665$, contestando os decretos municipais e estaduais que determinaram os fechamentos de suas fronteiras. A ANTT enviou ao STF um parecer se manifestando pela inconstitucionalidade das medidas.

${ }^{8}$ Segundo a ANAC (2020), o número de voos semanais previstos para o mês de abriu havia caído de 14.781 para 1.241.

${ }^{9}$ Regime de hospital-dia é a assistência intermediária entre a internação e o atendimento ambulatorial, para realização de procedimentos clínicos, cirúrgicos, diagnósticos e terapêuticos, que requeiram a permanência do paciente na unidade por um período máximo de 12 horas.
} 


\section{GRÁFICO 8 SUPORTE FINANCEIRO AOS AGENTES REGULADOS}

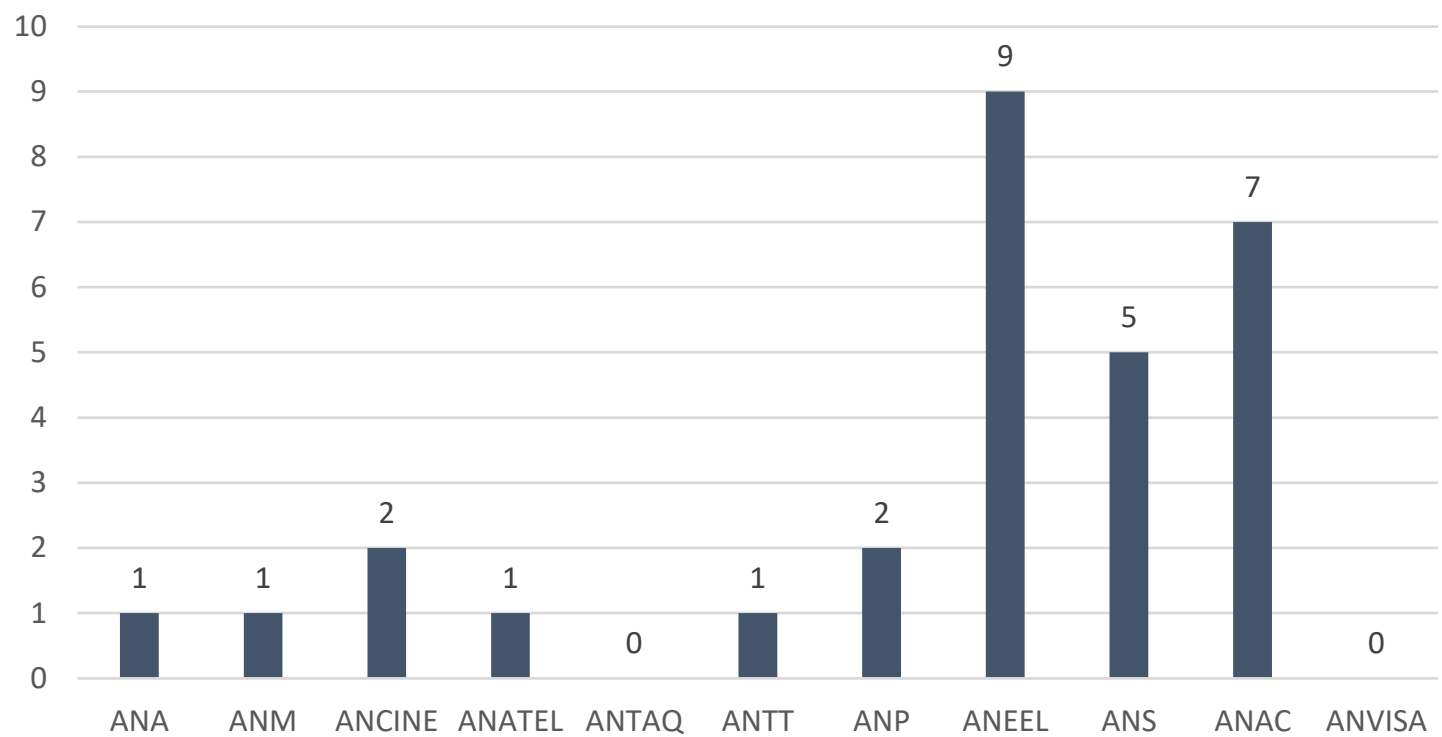

Fonte: Elaborado pelos autores.

A ANEEL autorizou a Câmara de Comercialização de Energia Elétrica (CCEE), por meio do Despacho $n^{\circ} 986$ (2020), a repassar às distribuidoras do Sistema Interligado Nacional (SIN) e a parte dos agentes do mercado livre recursos financeiros disponíveis no fundo de reserva. Estima-se que a medida proporcionará um alívio futuro de $\mathrm{R} \$ 2,022$ bilhões em encargos para distribuidoras e agentes do ambiente de contratação livre. Outras medidas adotadas pela agência para ampliar a liquidez do setor foram a antecipação dos efeitos financeiros da parcela de ajuste para os meses de abril, maio e junho de 2020, proporcionando descontos de $\mathrm{R} \$ 144$ milhões nos encargos de uso do sistema de distribuição (90\%) e consumidores livres (10\%), bem como o adiamento da cobrança da parcela de ineficiência por sobrecontratação das distribuidoras de 2019 para outubro de 2020, proporcionando uma economia de R 11 milhões.

A ANAC (2020) adiou para o mês de dezembro o recolhimento de outorgas das concessionárias administradoras de aeroportos, implementando orientação previamente estabelecida pela Medida Provisória no 925 (2020). Em seguida, celebrou com outros órgãos públicos e empresas aéreas um Termo de Ajustamento de Conduta (TAC) definindo as regras de remarcação, cancelamento e reembolso das passagens. Esse acordo foi celebrado com o objetivo de limitar os pedidos de reembolso e remarcação sem custo, bem como afastar a obrigação das companhias aéreas de fornecer assistência material com alimentação, hospedagem e traslado por atrasos e cancelamentos de voos em decorrência do fechamento de fronteiras. Esse TAC proibiu a Secretaria Nacional do Consumidor (Senacon) de aplicar multas às empresas aéreas signatárias por um período de 180 dias. 
A ANS decidiu flexibilizar uma série de normas prudenciais ${ }^{10} \mathrm{com}$ o objetivo de ampliar a liquidez das operadoras. Além de prorrogar prazos para a constituição de ativos garantidores, liberando cerca de R 1,7 bilhão para as operadoras, previu a flexibilização de outras normas prudenciais para as operadoras que aceitassem renegociar contratos de beneficiários inadimplentes e se comprometessem com o pagamento regular aos prestadores.

Para garantir maior liquidez do setor, a ANP facultou às empresas contratadas para a exploração e a produção de petróleo e gás natural a prorrogação de contrato por um período de 9 meses (Resolução $n^{\circ} 815,2020$ ). Já a Resolução nº 816 (2020) flexibilizou algumas obrigações contratuais dos operadores de exploração e produção de petróleo e gás natural, como a prorrogação de prazo para investimentos em pesquisa, desenvolvimento e inovação.

O comitê gestor do Fundo Setorial Audiovisual (FSA), do qual faz parte a Ancine, aprovou uma série de medidas emergenciais de amparo ao setor audiovisual, entre as quais se destacam a criação de um programa de apoio financeiro a pequenos exibidores e a aprovação de uma linha de crédito especial para o setor audiovisual a ser gerida pelo Banco Nacional de Desenvolvimento Econômico e Social (BNDES). O comitê aprovou a suspensão temporária de pagamentos para empresas do setor audiovisual que tenham operações ativas de crédito com o BNDES (Ancine, 2020).

A ANTT postergou a cobrança de verbas de fiscalização das concessionárias federais de infraestrutura rodoviária (Resolução $n^{\circ} 5.892,2020$ ). A ANM adotou medidas para desburocratizar o setor, e a Anatel suspendeu temporariamente multas e juros de seus regulados.

Por fim, a ANA interrompeu por um tempo a cobrança pela captação de água bruta em rios e reservatórios de domínio da União (Resolução no 18,2020$)$ e do próprio órgão. A medida foi adotada com o objetivo de beneficiar indústrias, produtores rurais, irrigantes e empresas de saneamento.

\subsubsection{Proteção aos usuários dos serviços em situação de fragilidade econômica}

Por fim, um número menor de agências também adotou providências para garantir a continuidade da prestação dos serviços aos usuários em situação de fragilidade econômica. O Gráfico 9 apresenta a quantidade de ações desse tipo por agência.

A ANEEL, por meio da Resolução no 878 (2020), foi a agência que mais se destacou na proteção dos usuários mais fragilizados. Uma das principais medidas adotadas foi a proibição da suspensão do fornecimento de energia elétrica em caso de inadimplência. Foi proibida a suspensão da energia fornecida a atividades classificadas como essenciais pelo governo federal, como clínicas, hospitais, presídios, serviços de call center e funerários, entre outros. Também foi proibida a suspensão do fornecimento de energia de residências urbanas e rurais.

\footnotetext{
${ }^{10}$ As normas prudenciais exigem que as operadoras forneçam garantias financeiras diante dos riscos da operação de plano de saúde. Essas garantias financeiras são traduzidas na exigência de provisões técnicas, ativos garantidores e recursos próprios mínimos, visando à liquidez e à solvência das operadoras para a continuidade e a qualidade do serviço contratado pelo beneficiário.
} 


\section{GRÁFICO 9 PROTEÇÃO AOS USUÁRIOS DOS SERVIÇOS}



Fonte: Elaborado pelos autores.

A Medida Provisória no 950 (2020) concedeu, por 3 meses, 100\% de desconto no valor da conta dos beneficiários de tarifa social que tivessem consumo igual ou inferior a $220 \mathrm{kWh} / \mathrm{mês}$. Essa norma também autorizou que a União repassasse recursos à Aneel para garantir a cobertura desses descontos.

A ANS, como visto, estabeleceu como condição para a flexibilização de normas prudenciais das operadoras a renegociação de contratos de beneficiários inadimplentes. Desse modo, algumas operadoras celebraram acordo com a ANS para movimentar recursos de fundos garantidores diversos sob a condição de renegociação desses contratos.

A ANAC, por meio do TAC celebrado com a Senacon e com empresas aéreas, garantiu aos consumidores o direito, sem nenhum custo adicional, a reembolso ou a remarcar passagens canceladas.

Diferentemente da ANEEL, no entanto, ANATEL e ANP não adotaram medidas para garantir a continuidade da prestação de serviços em caso de inadimplência dos usuários. A não interrupção de serviços para esse caso fora determinada por ações judiciais. O juiz da 12a Vara Cível Federal de São Paulo decidiu liminarmente, no âmbito da Ação Civil Pública no 500466232.2020.4.03.6100, que todas as prestadoras, concessionárias e autorizadas se abstivessem de suspender ou interromper o fornecimento dos serviços de telefonia fixa e móvel ao longo do período de emergência de saúde decorrente da crise do coronavírus e que restabelecessem serviços que recentemente tivessem sido cortados em razão de inadimplência. O presidente do Tribunal Regional Federal (TRF) da $3^{a}$ Região, no entanto, suspendeu os efeitos das referidas decisões liminares, restaurando a possibilidade de interrupção dos serviços de telefonia fixa e móvel por inadimplência.

Embora fuja ao escopo do presente artigo, as agências estaduais de abastecimento de água também estavam contempladas na referida decisão. Assim como ANATEL e ANP, elas permitiram a interrupção dos serviços em caso de inadimplemento dos usuários. 


\section{LIMITES E POSSIBILIDADES DAS RESPOSTAS REGULATÓRIAS}

As medidas adotadas em resposta à COVID-19 suscitam dificuldades operacionais singulares. A crise do novo coronavírus impõe às agências reguladoras respostas eficazes, tempestivas e, sobretudo, coordenadas.

A classificação das medidas das agências por tipo de ação empreendida nos permite fazer uma avaliação mais qualitativa do engajamento das diferentes agências com a COVID-19. O Gráfico 10 evidencia o percentual de ações que se enquadra em cada categoria, por agência, em valores de 0 a $1 .{ }^{11}$

\section{GRÁFICO 10 CLASSIFICAÇÃO DAS MEDIDAS DE COMBATE À COVID-19 POR AGÊNCIA}

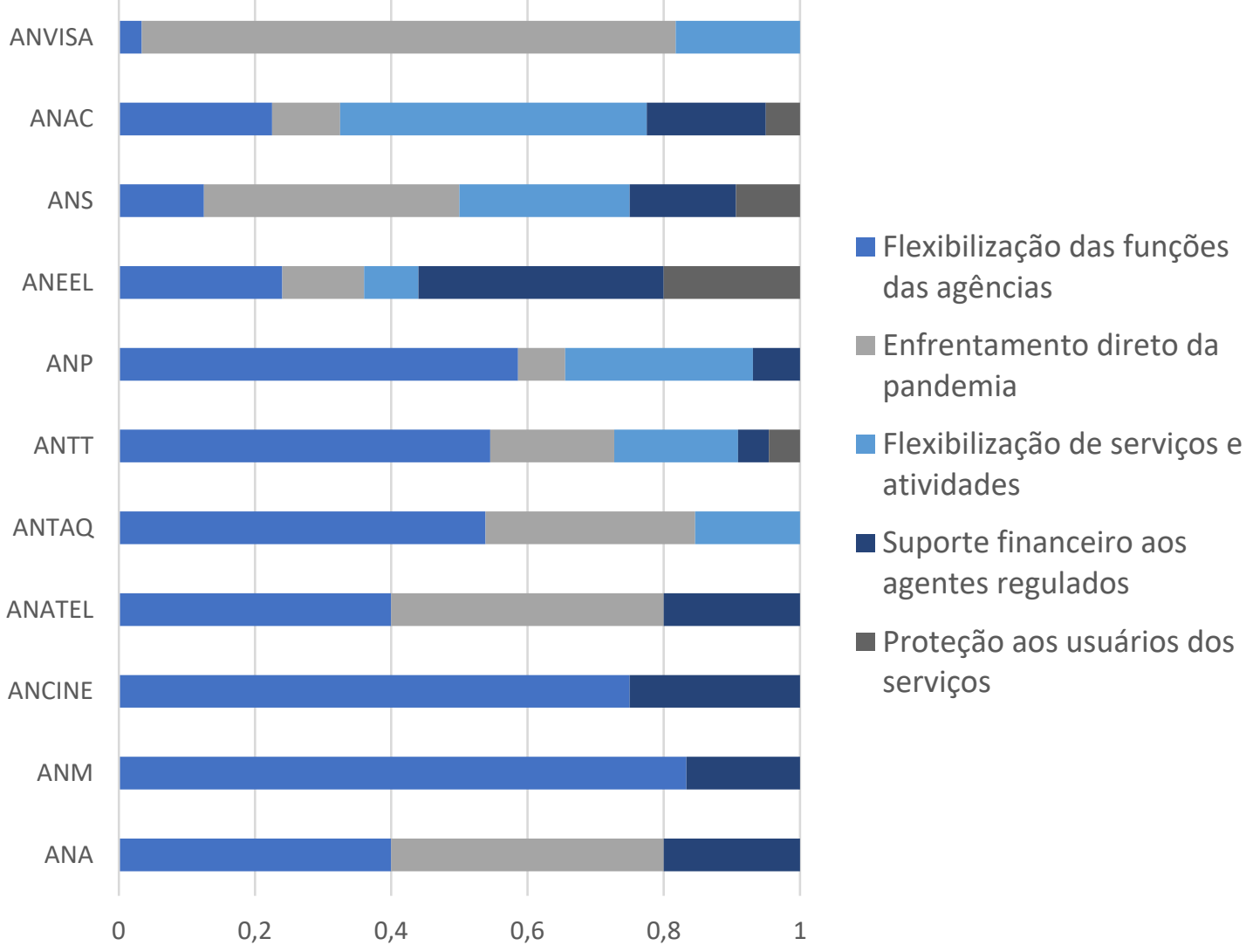

Fonte: Elaborado pelos autores.

Como já observado, todas as agências reguladoras federais adotaram medidas em decorrência da pandemia. Verificam-se, porém, diferenças consideráveis nas respostas oferecidas pelas agências. Em parte, isso se deve às diferenças setoriais das agências reguladoras analisadas.

\footnotetext{
${ }^{11}$ Os valores foram calculados em relação ao total de ações classificadas para cada agência, de forma a manter o total de $100 \%$ quando somadas todas as categorias de ação.
} 
Um fator relevante para o peso predominante da ANVISA no combate à COVID-19 é, evidentemente, a pertinência temática. Para além dessa constatação, é possível identificar o controle sanitário como um tema transversal que, no atual cenário de esforços para conter a disseminação do vírus, tem implicações relevantes para os mais diversos setores da economia e para as demais agências reguladoras. Referências a notas técnicas e resoluções tornaram frequentes em atos legislativos iniciados pelo Poder Executivo em geral, bem como em atos normativos e decisões administrativas das agências.

Diferentemente da ANVISA, algumas agências, como ANA, ANCINE e ANM, têm oferecido respostas tímidas em relação à pandemia.

Ao analisar o conteúdo das medidas adotadas, verifica-se que grande parte delas não trata diretamente do enfrentamento à doença. Em diversos casos, o coronavírus é apresentado como pano de fundo para a adoção de medidas que respondem aos efeitos indiretos da crise, ou seja, às restrições geradas para o exercício das atividades regulatórias das próprias agências, ocasionando suspensões de prazos processuais, relaxamento de obrigações para os regulados, suspensão de vistorias e fiscalizações etc. Desse modo, as agências têm deixado de exercer parte de suas funções regulatórias típicas para gerir os impactos da pandemia.

Além disso, essa gestão tem suscitado dificuldades operacionais singulares. Embora as agências atuem em setores distintos, em muitos casos se espera que elas ajam de forma coordenada (Bradley, 2011; Marisam, 2011). A coordenação parece funcionar satisfatoriamente entre a ANVISA e as agências de transporte, notadamente ANAC, ANTT e ANTAQ. Como visto, as medidas de vigilância sanitária determinadas pela ANVISA são essenciais para garantir a segurança de passageiros em portos, aeroportos e rodovias. Além disso, as agências reguladoras de transporte têm flexibilizado regras para garantir agilidade no transporte não só de insumos e materiais utilizados na prevenção e no tratamento da COVID-19 - por meio de táxis aéreos -, mas também no tratamento de pessoas portadoras da doença infecciosa.

A ANAC, a ANTT e a ANTAQ regulam, em suas respectivas áreas, o transporte interestadual de passageiros. Em razão da queda de demanda, elas deliberaram pela diminuição de viagens em suas respectivas malhas, mas não autorizaram a suspensão completa do serviço. Alguns estados e municípios, todavia, editaram decretos restringindo o transporte intermunicipal e interestadual em seus territórios. Conquanto a ANTT discorde dessas medidas restritivas, não dispõe de competência para se sobrepor às decisões desses entes. A estrutura federativa brasileira, sem dúvida, constitui um obstáculo adicional à coordenação da atuação das agências (Schmidt, Mello, \& Cavalcante, 2020). Torna-se imprescindível, desse modo, que as iniciativas de coordenação regulatória incorporem uma dimensão interfederativa.

Instrumentos de coordenação regulatória são necessários para resolver problemas de assimetria nas respostas oferecidas pelas agências a fim de garantir a continuidade dos serviços, a proteção dos usuários e a preservação dos direitos econômico-financeiros dos regulados. Por exemplo, as agências têm adotado providências para garantir que serviços públicos e atividades econômicas essenciais não sejam interrompidos enquanto perdurar a crise. Têm-se revelado comuns medidas para garantir a liquidez das concessionárias diante da queda de demanda, bem como ações para proteger os usuários impactados economicamente pela crise.

As agências têm oferecido, contudo, respostas distintas para problemas regulatórios semelhantes. Algumas têm adotado medidas para proteger usuários em situação de vulnerabilidade. A ANEEL, como 
visto, além de conceder 100\% de desconto aos beneficiários da tarifa social, proibiu a interrupção do fornecimento de energia em residências de usuários inadimplentes. Já a ANS anunciou que garantirá maior liquidez às operadoras que aceitarem renegociar contratos com beneficiários inadimplentes. ANATEL, ANP e diversas agências estaduais de abastecimento de água, porém, não adotaram medidas equivalentes. Elas têm resistido, inclusive em disputas judiciais, a proibir a interrupção desses serviços.

Dadas as diferenças setoriais dos alvos regulatórios das agências, é compreensível que elas ofereçam respostas distintas para garantir a continuidade dos serviços em tempo de pandemia. Cada agência reguladora deve adotar medidas específicas para garantir a liquidez das concessionárias e pactuar o reequilíbrio econômico financeiro de contratos, por exemplo. No entanto, não é razoável que essas agências tratem de forme diversa usuários de serviços essenciais como telefonia, energia, água e gás.

A literatura aponta alguns instrumentos de coordenação regulatória que poderiam ser utilizados para resolver problemas dessa natureza. Termos de compromisso, normas conjuntas e consultas recíprocas entre agências são algumas ferramentas possíveis para promover ações regulatórias coordenadas (Freeman \& Rossi, 2012; Kaiser, 2011). Instrumentos de coordenação regulatória são necessários para resolver problemas de assimetria nas respostas oferecidas pelas agências a fim de garantir a continuidade dos serviços, a proteção dos usuários e a preservação dos direitos econômicofinanceiros dos regulados.

A Lei Geral das Agências Reguladoras (Lei no 13.848, 2019) previu a possibilidade de articulação entre agências para que estas editem atos normativos conjuntos e estabeleçam ações colaborativas para o exercício de funções regulatórias. Em resposta à pandemia, procurou-se demonstrar que as agências têm feito uso desses instrumentos de maneira embrionária.

Essa articulação, entretanto, necessita ser fortalecida para que as agências possam enfrentar adequadamente a crise do coronavírus, que constitui uma oportunidade para a institucionalização, tanto por vias legais quanto administrativas, dos mecanismos essenciais de coordenação regulatória. 


\section{REFERÊNCIAS}

Agência Nacional de Aviação Civil. (2020, 22 de abril). Demanda doméstica por voos cai 32,9\% em março, após pandemia do novo coronavírus. Recuperado de https://www.anac.gov.br/noticias/2020/demandadomestica-por-voos-cai-32-9-em-marco-apospandemia-do-novo-coronavirus

Agência Nacional de Aviação Civil. (2020, 12 de maio). Postergado o pagamento de outorgas dos aeroportos de Guarulhos, Viracopos e Brasília. Recuperado de https://www.anac.gov.br/noticias/2020/postergadoo-pagamento-de-outorgas-dos-aeroportos-deguarulhos-viracopos-e-brasilia

Agência Nacional de Energia Elétrica. (2020, 08 de junho). Em teletrabalho, Aneel economiza $R \$ 15$ milhões dos cofres públicos e aumenta produtividade. Recuperado de bit.ly/2ziATnS

Agência Nacional de Vigilância Sanitária. (2020, 07 de maio). Nota da Anvisa sobre o PL 864/20. Recuperado de http://portal.anvisa.gov.br/web/ guest/noticias/-/asset_publisher/FXrpx9qY7FbU/ content/nota-da-anvisa-sobre-o-pl-86420/219201\#: :text=No\%20contexto $\% 20 \mathrm{da} \% 20$ aprova $\% \mathrm{C} 3 \% \mathrm{~A} 7 \% \mathrm{C} 3 \% \mathrm{~A} 3 \mathrm{o} \% 20 \mathrm{do}$,esclarece $\% 20$ o $\% 20$ que $\% 20$ se $\% 20$ segue $\% 3$ A \& text $=$ A $\% 20$ regula \% C $3 \%$ A 7 \% C $3 \%$ A 3 o \% 20 d a \% 20 Anvisa\% 20\%C3\%A9,\%2Dmercado\%20e\%20 p\%C3\%B3s\%2Dmercado

Agência Nacional do Cinema. (2020, 25 de junho). Comitê Gestor do FSA aprova medidas de amparo ao setor audiovisual. Recuperado de https://www. ancine.gov.br/pt-br/sala-imprensa/noticias/comitgestor-do-fsa-aprova-medidas-de-amparo-ao-setoraudiovisual

Alves, R. (2020, 09 de junho). ANA aumenta ritmo de regularização de usos de águas da União em 2020. Agência Nacional de Águas e Saneamento Básico. Recuperado de https://www.ana.gov.br/noticias/ ana-aumenta-ritmo-de-regularizacao-de-usos-deaguas-da-uniao-em-2020

Baldwin, R., Cave, M., \& Lodge, M. (2012). Understanding regulation: theory, strategy and practice (2a ed.). Oxford, UK: Oxford University Press.

Bradley, K. (2011). The Design of Agency Interactions. Columbia Law Review, 111(4), 745-794.
Coglianese, C., \& Walters, D. E. (2016). Agendasetting in the regulatory state: theory and evidence. Administrative Law Review, 68(1), 93-118.

Croda, J. H. R., \& Garcia, L. P. Resposta imediata da Vigilância em Saúde à epidemia da Covid-19. Epidemiologia e Serviços de Saúde, 29(1), 1-3.

Decisão $n^{o}$ 83, de 20 de abril de 2020. (2020). Autoriza, em caráter excepcional e temporário, alterações de aeronaves e transporte de passageiros usando dispositivos de isolamento de pacientes (Patient Isolation Device [PID]). Brasília, DF: Diário Oficial da União.

Decreto $n^{\circ}$ 10.139, de 28 de novembro de 2019. (2019). Dispõe sobre a revisão e a consolidação dos atos normativos inferiores a decreto. Brasília, DF: Diário Oficial da União. Recuperado de http:// www.planalto.gov.br/ccivil_03/_ato2019-2022/2019/ decreto/D10139.htm

Despacho $n^{\circ}$ 986, de 7 de abril de 2020. (2020). Brasília, DF: Diário Oficial da União.

Freeman J., \& Rossi, J. (2012). Agency Coordination in Shared Regulatory Space. Harvard Law Review, 125(2), 131-1211.

Kaiser, F. M. (2011). Interagency collaborative agreements and activities: types, rationales, considerations (CFS Report for Congress R 41803). Washington, DC: US Congress.

Kerwin, C., \& Furlong, S. R. (2018). Rulemaking: how government agencies write law and make policy (5 ed.). London, UK: Sage Publications.

Lei n. 8.987, de 13 de fevereiro de 2015. (2015). Dispõe sobre o regime de concessão e permissão da prestação de serviços públicos previsto no art. 175 da Constituição Federal, e dá outras providências. Brasília, DF: Diário Oficial da União.

Lei n. 13.848 de 25 de junho de 2019. (2019). Dispõe sobre a gestão, a organização, o processo decisório e o controle social das agências reguladoras, altera a Lei no 9.427, de 26 de dezembro de 1996, a Lei ${ }^{\circ}$ 9.472, de 16 de julho de 1997, a Lei no 9.478, de 6 de agosto de 1997, a Lei n ${ }^{\circ} 9.782$, de 26 de janeiro de 1999, a Lei $\mathrm{n}^{\circ} 9.961$, de 28 de janeiro de 2000, a Lei $\mathrm{n}^{\circ}$ 9.984, de 17 de julho de 2000, a Lei no 9.986, de 18 de julho de 2000, a Lei $n^{\circ} 10.233$, de 5 de junho de 2001, a Medida Provisória no 2.228-1, de 6 de setembro de 2001, a Lei ${ }^{\circ} 11.182$, de 27 de setembro 
de 2005, e a Lei no 10.180, de 6 de fevereiro de 2001. Brasília, DF: Diário Oficial da União. Recuperado de http://www.planalto.gov.br/ccivil_03/_Ato20192022/2019/Lei/L13848.htm

Lei $n$. 13.874, de 20 de setembro de 2019. (2019). Institui a Declaração de Direitos de Liberdade Econômica; estabelece garantias de livre mercado. Brasília, DF: Diário Oficial da União. Recuperado de http://www.planalto.gov.br/ccivil_03/_ato20192022/2019/lei/L13874.htm

Lei n. 13.989, de 15 de abril de 2020. (2020). Dispõe sobre o uso da telemedicina durante a crise causada pelo coronavírus (Sars-CoV-2). Brasília, DF: Diário Oficial da União. Recuperado de http://www. planalto.gov.br/ccivil_03/_Ato2019-2022/2020/Lei/ L13989.htm

Lodge, M. (2014). Regulatory capacity. In M. Lodge, \& K Wegrich (Eds.), The problem-solving capacity of the modern state. Oxford, UK: Oxford University Press.

Marisam, J. (2011). Duplicative Delegations. Administrative Law Review, 63(2), 181-244.

Marques, F. A., Neto. (2003). Agências Reguladoras: instrumentos do fortalecimento do Estado. Brasília, DF: Associação Brasileira de Agências de Regulação. Recuperado de http://abar.org.br/ mdocs-posts/agencias-reguladoras-instrumentosdo-fortalecimento-do-estado/

Matthews, F. (2012). Governance, governing and the capacity of executives in times of crisis. In M. Lodge, \& K Wegrich (Eds.), Executive Politics in Time of Crisis. Basingstoke, UK: Palgrave Macmillan.

Medida provisória no 925, de 18 de março de 2020. (2020). Dispõe sobre medidas emergenciais para a aviação civil brasileira em razão da pandemia da covid-19. Brasília, DF: Diário Oficial da União. Recuperado de http://www.planalto.gov.br/ ccivil_03/_ato2019-2022/2020/Mpv/mpv925.htm

Medida provisória no 950, de 8 de abril de 2020. (2020). Dispõe sobre medidas temporárias emergenciais destinadas ao setor elétrico para enfrentamento do estado de calamidade pública reconhecido pelo Decreto Legislativo $n^{\circ} 6$, de 20 de março de 2020, e da emergência de saúde pública de importância internacional decorrente da pandemia de coronavírus (covid-19). Brasília, DF: Diário
Oficial da União. Recuperado de http://www.in.gov. $\mathrm{br} / \mathrm{en} / \mathrm{web} / \mathrm{dou} /-/$ medida-provisoria-n-950-de-8de-abril-de-2020-251768271.

Organização para a Cooperação e o Desenvolvimento Econômico. (2020). Evaluating the initial impact of Covid-19 containment measures on economic activity. Paris, France: OCDE Publishing.

Organização para a Cooperação e o Desenvolvimento Econômico. (2020). A systemic resilience approach to dealing with Covid-19 and future shocks. Paris, France: OCDE Publishing.

Pereira, P. O. (2014). Análise da atuação internacional da Anvisa na perspectiva de seu corpo técnico e gerencial. Rio de Janeiro, RJ: Escola Nacional de Saúde Pública Sergio Arouca.

Portaria $n^{\circ} 74$, de 27 de janeiro de 2020. (2020). Dispõe sobre a criação de Grupo de Emergência em Saúde Pública para condução das ações referentes ao Novo Coronavírus (NCoV). Brasília, DF: Diário Oficial da União.

Portaria $n^{\circ}$ 102, de 12 de maio de 2020. (2020). Brasília, DF: Diário Oficial da União.

Portaria $n^{\circ}$ 109, de 18 de maio de 2020. (2020). Prorroga os prazos de medidas de combate à Covid-19. Brasília, DF: Diário Oficial da União.

Portaria no 117, de 25 de março de 2020. (2020). Brasília, DF: Diário Oficial da União.

Portaria no 125, de 19 de março de 2020. (2020). Brasília, DF: Diário Oficial da União.

Portaria $n^{\circ}$ 134, de 28 de março de 2020. (2020). Brasília, DF: Diário Oficial da União.

Portaria $n^{\circ}$ 152, de 27 de março de 2020 (2020). Dispõe sobre a restrição excepcional e temporária de entrada no País de estrangeiros, conforme recomendação da Agência Nacional de Vigilância Sanitária (Anvisa). Brasília, DF: Diário Oficial da União.

Portaria $n^{\circ}$ 157-e. Altera a Portaria Ancine no 151E, de 19 de março de 2020. (2020). Estabelece, em caráter excepcional, medidas administrativas para a mitigação dos impactos do Covid-19 no setor audiovisual e no que se refere às atribuições da Agência Nacional do Cinema (Ancine), nos limites de sua competência. Brasília, DF: Diário Oficial da União. 
Portaria $n^{\circ}$ 165, de 9 de junho de 2020. (2020). Institui o Comitê Gestor Monitoramento Covid Esgotos. Brasília, DF: Diário Oficial da União.

Portaria $n^{\circ}$ 467, de 20 de março de 2020. (2020). Dispõe, em caráter excepcional e temporário, sobre as ações de telemedicina, com o objetivo de regulamentar e operacionalizar as medidas de enfrentamento da emergência de saúde pública de importância internacional previstas no art. $3^{\circ} \mathrm{da}$ Lei $n^{\circ} 13.979$, de 6 de fevereiro de 2020, decorrente da epidemia de Covid-19. Brasília, DF: Diário Oficial da União.

Portaria $n^{\circ}$ 880/SPO, de 27 de março de 2020. (2020). Autoriza transporte de carga por operador certificado sob o RBAC nº 135. Brasília, DF: Diário Oficial da União.

Portaria $n^{\circ} 1.153$, de 19 de março de 2020. (2020). Cria o Comitê de Crise para Supervisão e Monitoramento dos Impactos da Covid-19 no âmbito das Comunicações (Rede conectada MCTIC) e estabelece diretrizes a serem adotadas pela Agência Nacional de Telecomunicações (Anatel). Brasília, DF: Diário Oficial da União.

Portaria $n^{\circ}$ 6.310, de 24 de março de 2020. (2020). Brasília, DF: Diário Oficial da União.

Portaria $n^{\circ}$ 47, de 26 de março de 2020. (2020). Dispõe sobre a restrição excepcional e temporária de entrada no País de estrangeiros por transporte aquaviário, conforme recomendação da Agência Nacional de Vigilância Sanitária (Anvisa). Brasília, DF: Diário Oficial da União.

Resolução CFM no 1.643/2002. (2002). Define e disciplina a prestação de serviços através da Telemedicina. Brasília, DF: Conselho Federal de Medicina. Recuperado de https://sistemas.cfm.org. br/normas/visualizar/resolucoes/BR/2002/1643

Resolução no 18, de 15 de abril 2020. (2020). Brasília, DF: Diário Oficial da União.

Resolução $n^{\circ} 21$, de 20 de abril de 2020. (2020). Dispõe sobre a prorrogação dos prazos de condicionantes e vigências de outorgas de uso de recursos hídricos, como medida emergencial de enfrentamento dos efeitos causados pela pandemia de Covid-19. Brasília, DF: Diário Oficial da União.

Resolução $n^{\circ}$ 347, de 12 de março de 2020. (2020). Define os critérios e os procedimentos extraordinários e temporários para a exposição à venda de preparações antissépticas ou sanitizantes oficinais, em virtude da emergência de saúde pública internacional relacionada ao Sars-CoV-2. Brasília, DF: Diário Oficial da União.

Resolução no 350, de 19 de março de 2020. (2020). Define os critérios e os procedimentos extraordinários e temporários para a fabricação e comercialização de preparações antissépticas ou sanitizantes oficinais sem prévia autorização da Anvisa e dá outras providências, em virtude da emergência de saúde pública internacional relacionada ao Sars-CoV-2. Brasília, DF: Diário Oficial da União.

Resolução no 355, de 23 de março de 2020. (2020). Dispõe sobre a suspensão dos prazos processuais afetos aos requerimentos de atos públicos de liberação de responsabilidade da Anvisa em virtude da emergência de saúde pública internacional relacionada ao Sars-CoV-2. Brasília, DF: Diário Oficial da União.

Resolução no 356, de 23 de março de 2020. (2020). Dispõe, de forma extraordinária e temporária, sobre os requisitos para a fabricação, importação e aquisição de dispositivos médicos identificados como prioritários para uso em serviços de saúde, em virtude da emergência de saúde pública internacional relacionada ao Sars-CoV-2. Brasília, DF: Diário Oficial da União.

Resolução no 364, de 01 de abril de 2020. (2020). Suspende os efeitos da Resolução de Diretoria Colegiada (RDC) no 302, de 13 de outubro de 2005, em caráter temporário e excepcional, para os Laboratórios Federais de Defesa Agropecuária (LFDA) que irão realizar análises para o diagnóstico da Covid-19. Brasília, DF: Diário Oficial da União.

Resolução no 556, de 13 de maio de 2020. (2020). Flexibiliza em caráter excepcional e temporário da aplicação de dispositivos da Resolução no 400, de 13 de dezembro de 2016, em decorrência dos efeitos da pandemia da Covid-19. Brasília, DF: Diário Oficial da União.

Resolução no 812, de 23 de março de 2020. (2020). Define procedimentos a serem adotados pelos agentes regulados pela ANP, enquanto durarem as medidas temporárias de enfrentamento da emergência de saúde pública de importância internacional decorrente do Coronavírus (Covid-19) 
estabelecidas por estados e municípios da federação. Brasília, DF: Diário Oficial da União.

Resolução $n^{\circ}$ 815, de 20 de abril de 2020. (2020). Faculta a prorrogação de prazos relativos aos contratos de exploração e produção de petróleo e gás natural. Brasília, DF: Diário Oficial da União.

Resolução no 816, de 20 de abril de 2020. (2020). Define procedimentos a serem adotados pelos agentes regulados pela ANP que atuam nas atividades de exploração e produção de petróleo e gás natural, enquanto perdurarem as medidas temporárias de enfrentamento da emergência de saúde pública de importância internacional decorrente do Coronavírus (Covid-19) estabelecidas pelo governo federal. Brasília, DF: Diário Oficial da União.

Resolução normativa $n^{\circ} 259$, de 17 de junho de 2011. (2011). Dispõe sobre a garantia de atendimento dos beneficiários de plano privado de assistência à saúde e altera a Instrução Normativa ${ }^{\circ} 23$, de $1^{\circ}$ de dezembro de 2009, da Diretoria de Normas e Habilitação dos Produtos. Brasília, DF: Diário Oficial da União.

Resolução normativa no 453, de 12 de março de 2020. (2020). Altera a Resolução Normativa no 428 , de 7 de novembro de 2020, que dispõe sobre o Rol de Procedimentos e Eventos em Saúde no âmbito da Saúde Suplementar, para regulamentar a cobertura obrigatória e a utilização de testes diagnósticos para infecção pelo Coronavírus. Brasília, DF: Diário Oficial da União.

Resolução normativa no 458 , de 26 de junho de 2020. (2020). Altera a Resolução Normativa no 428 , de 7 de novembro de 2017, que dispõe sobre o Rol de Procedimentos e Eventos em Saúde no âmbito da Saúde Suplementar, para regulamentar a cobertura obrigatória e a utilização de testes sorológicos para a infecção pelo coronavírus (Covid-19), em cumprimento a determinação judicial proferida nos autos da Ação Civil Pública nº 0810140 15.2020.4.05.8300. Brasília, DF: Diário Oficial da União.

Resolução normativa n 878, de 24 de março de 2020. (2020). Medidas para preservação da prestação do serviço público de distribuição de energia elétrica em decorrência da calamidade pública atinente à pandemia de coronavírus (Covid-19). Brasília, DF: Diário Oficial da União.

Resolução no 5.875, de 17 de março de 2020. (2020). Dispõe sobre as medidas para enfrentamento da emergência de saúde pública de importância internacional decorrente do coronavírus responsável pelo surto de 2019/2020, no âmbito do serviço de transporte rodoviário interestadual e internacional de passageiros. Brasília, DF: Diário Oficial da União.

Resolução no 5.878, de 26 de março de 2020. (2020). Suspende os prazos processuais no âmbito dos processos administrativos sancionadores de que trata a resolução ${ }^{\circ} 5.083$, de 27 de abril de 2016. Brasília, DF: Diário Oficial da União.

Resolução no 5.879, de 26 de março de 2020. (2020). Dispõe sobre a flexibilização de prazos para cumprimento de obrigações contratuais e regulatórias, em razão da emergência de saúde pública de importância internacional decorrente do coronavírus, no âmbito da infraestrutura e serviço de transporte ferroviário de cargas e do transporte rodoviário de cargas e de passageiros, e dá outras providências. Brasília, DF: Diário Oficial da União.

Resolução nº 5.891, de 26 de maio de 2020. (2020). Dispõe sobre a substituição das sessões presenciais de Reuniões Participativas ou Audiências Públicas por sessões públicas transmitidas por meio de videoconferência ou outro meio eletrônico, em razão do estado de emergência de saúde pública de importância internacional decorrente da pandemia da Covid-19. Brasília, DF: Diário Oficial da União.

Resolução no 7.653, de 31 de março de 2020. (2020). Revisa e consolida as medidas em resposta à emergência de saúde pública no âmbito do transporte aquaviário e das instalações portuárias em razão da epidemia do coronavírus (Covid-19). Brasília, DF: Diário Oficial da União.

Resolução no 7.784, de 5 de junho de 2020. (2020). Suspende os prazos pontualmente previstos na resolução normativa $n^{\circ} 32 / 2019$, na resolução normativa $n^{\circ} 29 / 2019$, na resolução normativa ${ }^{\circ}$ 28/2019 e na resolução $\mathrm{n}^{\circ} 3.274 / 2014$, bem como aqueles relacionados à contabilidade regulatória das administrações portuárias. Brasília, DF: Diário Oficial da União. 
Resolução-RE no 922, de 27 de março de 2020. (2020). Brasília, DF: Diário Oficial da União.

Salinas, N. S. C., \& Brelaz, G. (2020). Limites da AIR como Instrumento de Promoção da Liberdade Econômica. In A. J. C. Cunha, Filho, R. R. Picelli,
\& R. M. Maciel (Orgs.), Lei de liberdade econômica anotada. São Paulo, SP: Quartier Latin.

Schmidt, F., Mello, J., \& Cavalcante P. (2020). Estratégias de coordenação governamental na crise da Covid-19. Brasília, DF: Ipea.

\section{Sérgio Guerra}

http://orcid.org/0000-0002-2373-7369

Diretor e Professor Titular de Direito Administrativo da Escola de Direito do Rio de Janeiro da Fundação Getulio Vargas (FGV DIREITO RIO) no Programa de Pós-Graduação stricto sensu em Direito da Regulação (Mestrado e Doutorado); Pós-Doutorado na Yale Law School; Doutor e Mestre em Direito; Editor da Revista de Direito Administrativo (RDA); Coordenador do Curso International Business Law da University of California Irvine; Embaixador da Yale University no Brasil; Consultor Jurídico da Comissão de Direito Público da OAB/ RJ. E-mail: sergio.guerra@fgv.br

\section{Natasha Schmitt Caccia Salinas}

http://orcid.org/0000-0003-1012-1132

Professora do Programa de Pós-Graduação stricto sensu em Direito da Regulação e do curso de graduação da Escola de Direito do Rio de Janeiro da Fundação Getulio Vargas (FGV DIREITO RIO); Doutora e Mestre em Direito pela Universidade de São Paulo (USP); Master of Laws (LL.M.) pela Yale Law School.

E-mail: natasha.salinas@fgv.br

\section{Lucas Thevenard Gomes}

https://orcid.org/0000-0001-5011-4960

Pesquisador do Centro de Pesquisas em Direito e Economia (CPDE) da Escola de Direito do Rio de Janeiro da Fundação Getulio Vargas (FGV DIREITO RIO); Pós-graduado em Relações Internacionais e graduado em Direito pela Fundação Getulio Vargas (FGV). E-mail: lucas.gomes@fgv.br 